\title{
Association between Serum Alanine Transaminase and Cardiometabolic Risk in Overweight and Obese Children
}

\author{
Tahniyah Haq ${ }^{1, *}$, Muhammad Abdul Hannan², Muhammad Abul Hasanat ${ }^{1}$, and Muhammed Fariduddin ${ }^{1}$ \\ ${ }^{1}$ Department of Endocrinology, Bangabandhu Sheikh Mujib Medical University (BSMMU), Dhaka, Bangladesh \\ ${ }^{2} J u n i o r$ Consultant, Sherpur District Hospital, Sherpur, Bangladesh
}

*Corresponding author: Tahniyah Haq, Department of Endocrinology, Bangabandhu Sheikh Mujib Medical University, Shahbag, Dhaka 1000, Room 1620, 16th Floor, Block D, Bangladesh, Tel: +88-01677791735; E-mail: tahniyah81@bsmmu.edu.bd

Received: 03 Feb, 2020 | Accepted: 06 Mar, 2020 | Published: 13 Mar, 2020

Citation: Haq T, Hannan MA, Hasanat MA, Fariduddin M (2020) Association between Serum Alanine Transaminase and Cardiometabolic Risk in Overweight and Obese Children. Int J Endocrinol Metab Disord 6(1): dx.doi.org/10.16966/2380-548X.164

Copyright: (C) $2020 \mathrm{Haq} \mathrm{T,} \mathrm{et} \mathrm{al.} \mathrm{This} \mathrm{is} \mathrm{an} \mathrm{open-access} \mathrm{article} \mathrm{distributed} \mathrm{under} \mathrm{the} \mathrm{terms} \mathrm{of} \mathrm{the} \mathrm{Creative} \mathrm{Commons} \mathrm{Attribution} \mathrm{License,}$ which permits unrestricted use, distribution, and reproduction in any medium, provided the original author and source are credited.

\begin{abstract}
Background: Liver is a central organ in the pathogenesis of insulin resistance and increased cardiometabolic risk. Alanine transaminase reflects hepatocyte injury and steatosis.

Aim: To see the association between alanine transaminase and cardiometabolic risk in overweight and obese children.

Methods: The study was done in 88 overweight and obese 6-18 year old children from January 2017 to March 2018 . Serum alanine transaminase and cardiometabolic risk factors (obesity, hypertension, dyslipidaemia, insulin resistance, hyperuricaemia and raised C-reactive protein) were measured.

Results: Diastolic blood pressure $(77.49 \pm 9.44$ vs. $72.06 \pm 7.50 \mathrm{mmHg}, \mathrm{p}=0.006)$, insulin resistance $(5.22 \pm 4.36$ vs. $3.48 \pm 1.77, \mathrm{p}=0.016)$ and fasting plasma glucose ( $4.89 \pm 0.91$ vs. $4.53 \pm 0.55 \mathrm{mmol} / \mathrm{l}, \mathrm{p}=0.038)$ were significantly higher in participants with raised alanine transaminase. Alanine transaminase increased with increasing waist circumference $(r=0.263, p=0.013)$, systolic blood pressure $(r=0.258, p=0.015)$, diastolic blood pressure

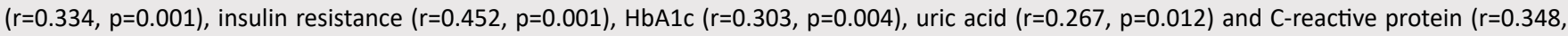
$p=0.001)$. After adjusting for cardiometabolic risk factors, only insulin resistance $(\beta=3.01, p<0.001)$ and uric acid $(\beta=4.99, p=0.015)$ were related with alanine transaminase. In addition, alanine transaminase was higher in those with metabolic syndrome $(39.07 \pm 25.94 \mathrm{vs}$. $28.48 \pm 19.27 \mathrm{U} / \mathrm{L}, \mathrm{p}=0.033)$.

Conclusion: Elevated alanine transaminase was associated with cardiometabolic risk, particularly insulin resistance and raised uric acid.
\end{abstract}

Keywords: Alanine transaminase; Insulin resistance; Cardiometabolic risk; Obesity

\section{Introduction}

Alanine transaminase (ALT) is the most important enzyme/marker of hepatocyte injury [1]. It also reflects fat accumulation in the liver [2]. Hepatic insulin resistance leads to deposition of fat in the liver. It also causes hyperglycaemia, hyperinsulinaemia by impaired inhibition of glucose production and dyslipidaemia by increased VLDL synthesis. Several studies have shown an association between ALT and different cardiometabolic risk factors such as insulin resistance, dyslipidaemia, hypertension and obesity in the adult population [3-8].

It is evident that the liver is a central organ in the pathogenesis of insulin resistance and increased cardiometabolic risk. Since ALT is a marker of liver injury, we wanted to investigate the relation of this enzyme with cardiometabolic risk. Furthermore, as there is limited data in the pediatric population, the aim of the study was to determine the 1) Association between ALT and cardiometabolic risk and 2) Cardiometabolic risk factors predicting elevated ALT in overweight and obese children.

\section{Material and Methods}

Overweight and obese 6-18 year old children were recruited at Bangabandhu Sheikh Mujib Medical University (BSMMU) from January 2017 to March 2018 by purposive non-probability sampling. Those with secondary obesity, liver disorders in last four weeks and drugs altering liver function, alcohol intake and family history of liver disease were excluded. The study was approved by Institutional Research Board, BSMMU (No. BSMMU/2017/24).Written informed assent was taken from each participant.

\section{Study design}

Overweight and obesity was determined by calculating body mass index (BMI) which was plotted on Centers for Disease Control (CDC) chart. ALT was measured and fatty liver was determined by ultrasonography. Participants were divided into 2 groups depending on their level of ALT. Cardiometabolic risk factors (central obesity, hypertension, impaired fasting glucose or diabetes mellitus, insulin resistance, dyslipidemia, raised uric acid and C-reactive protein 
(CRP)) were determined by clinical examination and laboratory investigation.

\section{Study procedure}

Weight was measured using an electronic digital weighing machine to the nearest $0.1 \mathrm{~kg}$, with the participant wearing light clothes and without shoes. Height was measured by a portable wall-mounted stadiometer to the nearest $0.1 \mathrm{~cm}$ with the participant without shoes in the erect position, back against the wall with his/her head held in Frankfurt horizontal plane with a right-angled triangle resting on the scalp and against the wall. Waist circumference (WC) was measured midway between the lowest rib and the superior border of the iliac crest by using a non-extensible and non-elastic measuring tape in mid respiration and inferences were drawn in percentiles. Waist height ratio (WHtR) was calculated by the formula WC in centimeters divided by body height in centimeters [9]. Blood pressure was measured according to method described by the Seventh Report of the Joint National Committee [10]. It was measured three times by the same individual with aneroid sphygmomanometer (Yamasu) after calibration and standardization and mean value was recorded. Ten $\mathrm{ml}$ of venous blood was collected after a 12 hour fast for ALT, fasting glucose, fasting insulin, $\mathrm{HbA1C}$, lipid profile, uric acid and CRP. ALT and uric acid were measured by enzymatic method using Beckman Coulter AU680. Glucose was measured by hexokinase/G6-PDH method. Quantitative determination of serum insulin levels was done by chemiluminescent immunoassay method using Access Immunoassay System (REF- 33410) and HbAlc was measured using the NGSP certified method (Bio-Rad D-10TM Hemoglobin Alc Program 220-0101, USA). Cardiophase CRP reagent was used for the quantitative determination of CRP in human serum by means of particle enhanced immune nephelometry (BN 2 and $\mathrm{BN}$ prospec system). Total cholesterol (TC), triglyceride (TG), and high density lipoprotein (HDL) were measured by automated analyzer (Architect Plus ci8200). Low density lipoprotein (LDL) was calculated with the use of the Friedewald formula: LDL-C=TC-HDL-C-(TG/5). The Homeostasis model assessment of insulin resistance (HOMA-IR) index (a measure of insulin resistance) was calculated as the product of the fasting plasma insulin level $(\mathrm{mU} / \mathrm{L})$ and the fasting plasma glucose level $(\mathrm{mM} / \mathrm{L})$, divided by 22.5 [11]. USG of hepatobiliary system (HBS) was done to determine the presence or absence of liver fat by an experienced sonologist.

\section{Operational definition}

The CDC age- and sex-specific growth chart was used to classify participants as overweight and obese. Overweight was defined as body mass index (BMI) at or greater than $85^{\text {th }}$ to less than $95^{\text {th }}$ percentile and obesity as BMI at or greater than $95^{\text {th }}$ percentile for age and sex [12]. Raised ALT was defined as $>25.8 \mathrm{U} / \mathrm{L}$ in boys and $22.1 \mathrm{U} / \mathrm{L}$ in girls, which corresponds to $95^{\text {th }}$ percentile [13]. Fatty liver was detected by ultrasound evidence of fatty changes in the liver. Because the BMI varies according to age, we standardized the value for age and sex with the use of conversion to a $\mathrm{z}$ score from the website [14]. Central obesity was defined as waist circumference (WC) $\geq 90$ percentile and/or waist height ratio $(\mathrm{WHtR}) \geq 0.5$ [15]. Hypertension was taken as systolic and/or a diastolic blood pressure $\geq 95^{\text {th }}$ percentile for age, gender, and height according to the "Fourth Report on Diagnosis, Evaluation, and Treatment of High Blood Pressure in Children and Adolescents $[16,17]$. HOMA-IR value above 3 (corresponds to the $95^{\text {th }}$ percentile healthy reference children) was regarded as presence of insulin resistance [18]. Impaired fasting glucose (IFG) was defined as fasting plasma glucose (FPG) levels between 5.6 and $6.9 \mathrm{mmol} / \mathrm{l}$ and diabetes when FPG $\geq 7 \mathrm{mmol} / \mathrm{l}$ [19]. Dyslipidemia was defined as at least one abnormal blood lipid value for HDL, LDL, TC, or TG [20]. Table 1 below shows abnormal cutoffs of individual blood lipids in children. The cut point of raised CRP for increased cardiovascular risk was taken at $2 \mathrm{mg} / \mathrm{l}[21,22]$. The cut point for elevated uric acid was taken at 5.5 [23]. The definition for metabolic syndrome in children was taken from National Cholesterol Education program (NCEP) [15] in which children must have at least three of the given criteria: 1) Serum Triglyceride $\geq 110 \mathrm{mg} / \mathrm{dL}, 2$ ) Serum HDL-C $\leq 40 \mathrm{mg} / \mathrm{dL}$, 3) Fasting plasma glucose $\geq 100 \mathrm{mg} / \mathrm{dL}$, 4) Waist circumference $\geq 90^{\text {th }}$ percentile for age and gender and 5) systolic or diastolic blood pressure $\geq 90^{\text {th }}$ percentile for age and sex.

\section{Statistical analysis}

All values were expressed as mean $\pm \mathrm{SD}$ or frequencies. Students independent $t$ test and one way ANOVA was used to compare the means of cardio-metabolic risks among participants with different levels of ALT. The correlation between two variables was studied with the Pearson's correlation coefficient test. Multiple linear regression (backward method) and logistic regression were used to evaluate the association between cardiometabolic risk factors and ALT. The SPSS version 23.0 was used for the statistical analyses.

\section{Results}

The study included 88 participants. The mean ALT level was 35.82 $\pm 24.47 \mathrm{U} / \mathrm{L}$, with a range of 11 to $127 \mathrm{U} / \mathrm{L} .54$ (61.4\%) had raised ALT, 47 (53.4\%) had fatty liver, and $30(34.1 \%)$ had both raised ALT and fatty liver (Figure 1).

Table 1: Plasma lipid ranges for children and adolescents [20].
\begin{tabular}{|l|c|c|c|}
\hline Category & Acceptable (mg/dl) & Borderline (mg/dl) & High(mg/dl) \\
\hline TC & $<170$ & $170-199$ & $\geq 200$ \\
\hline LDL-C & $<110$ & $110-129$ & $\geq 130$ \\
\hline HDL-C & $>45$ & $45-40$ & $<40$ \\
\hline \multicolumn{4}{|c|}{ TG (years) } \\
\hline $0-9$ & $<75$ & $75-99$ & $\geq 100$ \\
\hline $10-19$ & $<90$ & $90-129$ & $\geq 130$ \\
\hline
\end{tabular}

Table 2: Cardio-metabolic risk factors in the study population $(n=88)$.

\begin{tabular}{|l|c|c|c|}
\hline \multicolumn{1}{|c|}{ Variables } & $\begin{array}{c}\text { Elevated ALT } \mathbf{n = 5 4} \\
\text { Mean } \pm \text { SD }\end{array}$ & $\begin{array}{c}\text { Normal ALT } \mathbf{n = 3 4} \\
\text { Mean } \pm \text { SD }\end{array}$ & P value \\
\hline Age (years) & $11.56 \pm 2.75$ & $11.35 \pm 2.70$ & 0.74 \\
\hline BMI z score & $2.21 \pm 0.33$ & $2.16 \pm 0.40$ & 0.52 \\
\hline WC (cm) & $93.94 \pm 12.37$ & $90.59 \pm 10.51$ & 0.19 \\
\hline WHtR & $0.622 \pm 0.06$ & $0.617 \pm 0.05$ & 0.69 \\
\hline SBP (mmHg) & $111.48 \pm 13.36$ & $107.44 \pm 10.07$ & 0.13 \\
\hline DBP (mmHg) & $77.49 \pm 9.44$ & $72.06 \pm 7.50$ & $\mathbf{0 . 0 0 6}$ \\
\hline HOMA-IR & $5.22 \pm 4.36$ & $3.48 \pm 1.77$ & $\mathbf{0 . 0 1 6}$ \\
\hline FPG (mmol/l) & $4.89 \pm 0.91$ & $4.53 \pm 0.55$ & $\mathbf{0 . 0 3 8}$ \\
\hline HbA1c (\%) & $5.73 \pm 0.83$ & $5.50 \pm 0.42$ & 0.14 \\
\hline TC (mg/dl) & $170.31 \pm 35.36$ & $191.59 \pm 45.75$ & 0.016 \\
\hline LDL-C (mg/dl) & $104.34 \pm 27.81$ & $119.21 \pm 46.31$ & 0.09 \\
\hline HDL-C (mg/dl) & $36.85 \pm 8.84$ & $38.47 \pm 5.90$ & 0.31 \\
\hline TG (mg/dl) & $154.94 \pm 69.43$ & $176.71 \pm 131.32$ & 0.38 \\
\hline Uric acid (mg/dl) & $5.46 \pm 1.29$ & $5.12 \pm 1.09$ & 0.20 \\
\hline CRP (mg/dl) & $7.72 \pm 7.81$ & $7.09 \pm 6.90$ & 0.70 \\
\hline
\end{tabular}

Comparison by student's independent t test 
Table 3: Frequency of cardio-metabolic risk factors in study population $(n=88)$.

\begin{tabular}{|c|c|c|c|}
\hline Variables & $\begin{array}{c}\text { Elevated ALT } n=54 \\
n(\%)\end{array}$ & $\begin{array}{c}\text { Normal ALT } n=34 \\
n(\%)\end{array}$ & $P$ value \\
\hline Systolic HTN/Pre HTN & $13(24.1)$ & $5(14.7)$ & 0.42 \\
\hline Diastolic HTN/Pre HTN & $30(55.6)$ & $11(32.4)$ & 0.03 \\
\hline Prediabetes/diabetes & $06(11.1)$ & $01(2.9)$ & 0.24 \\
\hline Insulin resistance & $31(64.6)$ & $17(51.5)$ & 0.26 \\
\hline Raised TC & $28(51.9)$ & $21(61.8)$ & 0.39 \\
\hline Raised LDL & $23(42.6)$ & $15(44.1)$ & 1 \\
\hline Low HDL & $44(81.5)$ & $28(82.5)$ & 1 \\
\hline Raised TG & $47(87.0)$ & 31 (91.2) & 0.74 \\
\hline Raised uric acid & $23(42.6)$ & $10(29.4)$ & 0.15 \\
\hline Raised CRP & $44(81.5)$ & $28(82.4)$ & 1 \\
\hline
\end{tabular}

Comparison by chi square test.

Table 4: Comparison of cardio-metabolic risk factors among 3 tertiles of ALT ( $n=88)$.

\begin{tabular}{|c|c|c|c|c|}
\hline ALT & $1^{\text {st }}$ tertile $<22 \mathrm{U} / \mathrm{L}(\mathrm{n}=31)$ & $2^{\text {nd }}$ tertile $22-36.3 \mathrm{U} / \mathrm{L}(\mathrm{n}=28)$ & $3^{\text {rd }}$ tertile $>36.3 \mathrm{U} / \mathrm{L}(\mathrm{n}=29)$ & p value \\
\hline BMI z score & $2.18 \pm 0.43$ & $2.12 \pm 0.26$ & $2.29 \pm 0.37$ & 0.19 \\
\hline $\mathrm{WC}(\mathrm{cm})$ & $90.89 \pm 11.19$ & $89.26 \pm 7.83$ & $97.97 \pm 14.02$ & 0.009 \\
\hline WHtR & $0.617 \pm 0.05$ & $0.603 \pm 0.05$ & $0.641 \pm 0.06$ & 0.03 \\
\hline $\mathrm{SBP}(\mathrm{mmHg})$ & $108.50 \pm 10.33$ & $107.27 \pm 12.75$ & $114.12 \pm 12.83$ & 0.07 \\
\hline $\mathrm{DBP}(\mathrm{mmHg})$ & $72.43 \pm 7.77$ & $73.91 \pm 7.96$ & $79.83 \pm 9.95$ & 0.004 \\
\hline FPG (mmol/l) & $4.53 \pm 0.53$ & $4.72 \pm 0.57$ & $4.99 \pm 1.12$ & 0.09 \\
\hline HOMA-IR & $3.44 \pm 1.84$ & $3.44 \pm 1.88$ & $6.91 \pm 5.24$ & 0.001 \\
\hline HbA1c (\%) & $5.46 \pm 0.41$ & $5.53 \pm 0.35$ & $5.92 \pm 1.07$ & 0.03 \\
\hline $\mathrm{TC}(\mathrm{mg} / \mathrm{dl})$ & $189.18 \pm 38.17$ & $169.87 \pm 43.35$ & $177.52 \pm 39.44$ & 0.12 \\
\hline TG (mg/dl) & $180.54 \pm 143.76$ & $138.48 \pm 53.86$ & $173.34 \pm 75.38$ & 0.13 \\
\hline LDL-C (mg/dl) & $115.02 \pm 40.37$ & $105.69 \pm 39.23$ & $110.01 \pm 29.83$ & 0.63 \\
\hline $\mathrm{HDL}-\mathrm{C}(\mathrm{mg} / \mathrm{dl})$ & $38.57 \pm 6.33$ & $37.87 \pm 7.78$ & $36.00 \pm 9.15$ & 0.42 \\
\hline Uric acid (mg/dl) & $5.16 \pm 1.01$ & $5.08 \pm 1.23$ & $5.76 \pm 1.32$ & 0.07 \\
\hline CRP (mg/dl) & $7.23 \pm 7.52$ & $6.54 \pm 4.21$ & $8.72 \pm 9.78$ & 0.82 \\
\hline
\end{tabular}

Comparison done by one-way ANOVA. Tukey's post hoc analysis showed significant difference in WC and WHtR between $2^{\text {nd }} v s$. $3^{\text {rd }}$ tertile In DBP between $1^{\text {st }} v s .3^{\text {rd }}$ and $2^{\text {nd }} v s .3^{\text {rd }}$ tertile In HOMA-IR between $1^{\text {st }} v s .3^{\text {rd }}$ and $2^{\text {nd }} v s$. $3^{\text {rd }}$ tertile In $\mathrm{HbA} 1 \mathrm{c}$ between $1^{\text {st }} v s .3^{\text {rd }}$ tertile

Table 5: Comparison of ALT between participants with and without metabolic syndrome $(n=88)$.

\begin{tabular}{|l|c|c|c|}
\hline Variables & $\begin{array}{c}\text { Metabolic syndrome } \\
\text { present } \\
(\mathbf{n}=61) \text { Mean } \pm \text { SD }\end{array}$ & $\begin{array}{c}\text { Metabolic } \\
\text { syndrome absent } \\
(\mathbf{n}=27) \text { Mean } \pm \text { SD }\end{array}$ & p-value \\
\hline ALT (U/L) & $39.07 \pm 25.94$ & $28.48 \pm 19.27$ & $\mathbf{0 . 0 3}$ \\
\hline
\end{tabular}

Comparison by student's independent t test.

Diastolic blood pressure $(77.49 \pm 9.44$ vs. $72.06 \pm 7.50 \mathrm{mmHg}$ $\mathrm{p}=0.006)$, HOMA-IR $(5.22 \pm 4.36$ vs. $3.48 \pm 1.77, \mathrm{p}=0.016)$ and fasting plasma glucose $(4.89 \pm 0.91$ vs. $4.53 \pm 0.55 \mathrm{mmol} / \mathrm{l}, \mathrm{p}=0.038)$ were significantly higher in participants with raised ALT (Table 2).

Significantly greater number of participants with elevated ALT had diastolic hypertension (55.6 vs. 32.4\%, $\mathrm{p}=0.028$ ) (Table 3 ).

Participants in the highest tertile of ALT had a significantly greater WC, WHtR, DBP, HOMA-IR and HbAlc than the lower tertiles (Table 4).
ALT was significantly higher in children with metabolic syndrome $(39.07 \pm 25.94$ vs. $28.48 \pm 19.27 \mathrm{U} / \mathrm{L}, \mathrm{p}=0.033)$ (Table 5).

There was a significant positive correlation between ALT and WC $(\mathrm{r}=0.263, \mathrm{p}=0.013)$, SBP $(\mathrm{r}=0.258, \mathrm{p}=0.015), \mathrm{DBP}(\mathrm{r}=0.334, \mathrm{p}=0.001)$, HOMA-IR ( $\mathrm{r}=0.452, \mathrm{p}=0.001), \mathrm{HbA1c}(\mathrm{r}=0.303, \mathrm{p}=0.004)$, uric acid $(\mathrm{r}=0.267, \mathrm{p}=0.012), \mathrm{CRP}(\mathrm{r}=0.348, \mathrm{p}=0.001)$ (Table 6).

There was a significant relation of ALT with HOMA-IR and uric acid after adjusting for BMI, waist circumference, blood pressure, plasma glucose, blood lipids and CRP. ALT increases by 3.01 and 4.99 U/L when HOMA-IR and uric acid increase by 1 unit respectively $($ ALT $=-4.39+3.01$ HOMA-IR+4.99 uric acid) (Table 7).

Cardiometabolic risk factors did not significantly increase risk of having raised ALT and accounted for only $13 \%$ of its variance (Table 8 ).

\section{Discussion and Conclusion}

This study examined the association between ALT and cardiometabolic risk factors in overweight and obese children. We 
Table 6: Correlation of ALT with cardiometabolic risk factors $(n=88)$.

\begin{tabular}{|l|c|c|}
\hline \multicolumn{1}{|c|}{ Variables } & $\mathbf{r}$ & P value \\
\hline BMI z score & 0.025 & 0.82 \\
\hline WC (cm) & 0.263 & $\mathbf{0 . 0 1 3}$ \\
\hline WHtR & 0.185 & 0.08 \\
\hline SBP (mmHg) & 0.258 & $\mathbf{0 . 0 1 5}$ \\
\hline DBP (mmHg) & 0.334 & $\mathbf{0 . 0 0 1}$ \\
\hline FPG (mmol/l) & -0.021 & 0.84 \\
\hline HOMA-IR & 0.452 & $\mathbf{0 . 0 0 1}$ \\
\hline HbA1c (\%) & 0.303 & $\mathbf{0 . 0 0 4}$ \\
\hline TC (mg/dl) & 0.061 & 0.57 \\
\hline LDL-C (mg/dl) & 0.011 & 0.92 \\
\hline HDL-C (mg/dl) & -0.067 & 0.53 \\
\hline TG (mg/dl) & 0.144 & 0.18 \\
\hline Uric acid (mg/dl) & 0.267 & $\mathbf{0 . 0 1 2}$ \\
\hline CRP (mg/dl) & 0.348 & $\mathbf{0 . 0 0 1}$ \\
\hline
\end{tabular}

Table 7: Multiple linear regression with ALT as dependent variable $(n=88)$.

\begin{tabular}{|l|c|c|}
\hline \multicolumn{1}{|c|}{ Cardiometabolic risk factor } & Beta & P value \\
\hline HOMA-IR & 3.01 & $<0.001$ \\
\hline Uric acid $(\mathrm{mg} / \mathrm{dl})$ & 4.99 & 0.015 \\
\hline
\end{tabular}

Table 8: Logistic regression with raised ALT as dependent variable $(n=88)$.

\begin{tabular}{|l|c|c|}
\hline \multicolumn{1}{|c|}{ Cardiometabolic risk factor } & (Exp B) OR & P value \\
\hline Systolic hypertension & 0.78 & 0.74 \\
\hline Diastolic hypertension & 3.05 & 0.06 \\
\hline Prediabetes/diabetes & 6.87 & 0.12 \\
\hline Insulin resistance & 1.16 & 0.78 \\
\hline Raised TC & 0.61 & 0.46 \\
\hline Raised LDL & 1.03 & 0.96 \\
\hline Low HDL & 0.72 & 0.39 \\
\hline Raised TG & 1.23 & 0.64 \\
\hline Raised uric acid & 1.85 & 0.27 \\
\hline Raised CRP & 0.92 & 0.92 \\
\hline
\end{tabular}

found that waist circumference, WHtR, diastolic blood pressure and insulin resistance were higher in those with elevated ALT, irrespective of fatty liver. ALT increased with increasing waist circumference, systolic and diastolic blood pressure, insulin resistance, uric acid and CRP. However, after adjusting for cardiometabolic risk factors, only insulin resistance and uric acid were related with ALT. In addition, ALT was higher in those with metabolic syndrome.

Waist circumference was higher in those with elevated ALT. This was also found in another study [3]. There is a positive association between BMI, waist circumference and waist: hip ratio with nonalcoholic fatty liver disease $[7,24]$. There is a significant correlation between pediatric visceral adiposity index (which includes waist circumference) and ALT [25]. AST, ALT and GGT are related to hepatic steatosis in healthy Asians [26].

Diastolic blood pressure was higher in those with elevated ALT and predicted development of raised ALT with fatty liver. Other studies have shown similar results between blood pressure and ALT $[3,27]$. Contrary to this study, blood pressure was shown to increase across quartiles of ALT and GGT, but only GGT increased risk of

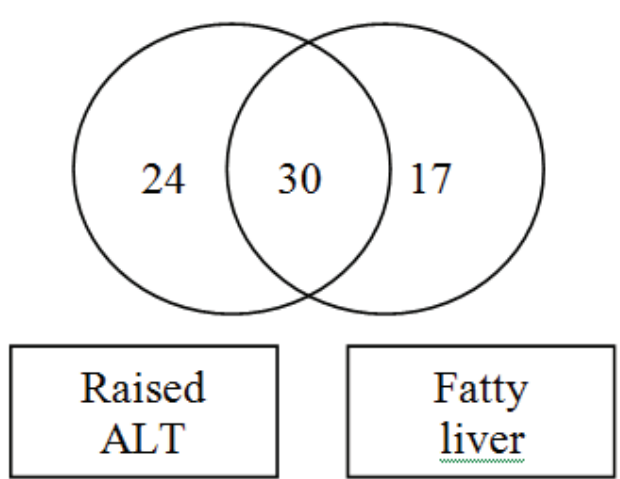

Figure 1: Distribution of participants with elevated ALT and fatty liver.

hypertension [28]. Carotid-femoral pulse wave velocity and blood pressure were higher in people with raised ALT levels [29]. Hepatic insulin resistance may play a role in explaining the relation between elevated liver enzymes and hypertension, as it is associated with an increased risk of incident hypertension [28].

Uric acid was higher in those with elevated ALT and fatty liver. It was related to ALT after adjusting for other cardiometabolic risk factors. Similar to this study, Chen S, et al. found that raised uric acid increased risk of altered ALT [3].

Insulin resistance was higher in those with elevated ALT. Furthermore, HOMA-IR was linearly related with ALT after adjusting for other cardiometabolic risk factors. Elevated HOMA-IR also increased risk of developing raised ALT with fatty liver. This is in accordance with other studies which have shown that HOMA-IR is significantly correlated with liver function markers [4]. Patients with raised ALT are also more prone to develop diabetes and metabolic syndrome [5]. However, a three year cohort study has shown that gamma-glutamyltransferase (GGT), and not ALT predicted risk of developing diabetes [2].

ALT was found to be higher in patients with metabolic syndrome. Both ALT and GGT, but not AST strongly predict metabolically unhealthy obesity [6]. There is a greater risk of developing metabolic syndrome and increased 10 year ASCVD risk in individuals with higher normal ALT levels [30]. On the other hand, metabolic syndrome increased risk of both steatohepatitis and hepatocyte injury [31].

The limitation of the study is that extensive investigations to determine causes of raised ALT were not done. Other markers of liver function were not addressed.

In conclusion, there is an association between cardiometabolic risk and ALT, particularly insulin resistance, uric acid and blood pressure.

\section{Acknowledgement}

We would like to thank BSMMU for funding the research and the department of Microbiology and Biochemistry, BSMMU for their technical support.

\section{Conflict of Interest}

None of the authors have any conflict of interest. 


\section{References}

1. Detour DR, Lott JA, Nolte FS, Gretch DR, Koff RS, et al. (2000) Diagnosis and monitoring of hepatic injury. I. Performance characteristics of laboratory tests. Clin Chem 46: 2027-2049.

2. Andre P, Balkau B, Born C, Royer B, Wilpart E, et al. (2005) Hepatic markers and development of type 2 diabetes in middle aged men and women: a three-year follow-up study The DESIR study (Data from an Epidemiological Study on the Insulin Resistance syndrome). Diabetes \& Metab 31: 542-550.

3. Chen S, Guo X, Zhang X, Yu S, Yang H, et al. (2015) Association between elevated serum alanine aminotransferase and cardiometabolic risk factors in rural Chinese population: a cross-sectional study. BMC Cardiovasc Disord 15: 65.

4. Gray B, Muhlhausler BS, Davies PS, Vitetta L (2013) Liver enzymes but not free fatty acid levels predict markers of insulin sensitivity in overweight and obese, nondiabetic adults. Nutr Res 33: 781-788.

5. Adams LA, Waters OR, Knuiman MW, Elliott RR, Olynyk JK (2009) NAFLD as a risk factor for the development of diabetes and the metabolic syndrome: an eleven-year follow-up study. Am J Gastroenterol 104: 861-867.

6. Xie J, Zhang S, Yu X, Yang Y, Liu Z, et al. (2018) Association between Liver Enzymes with Metabolically Unhealthy Obese Phenotype. Lipids Health Dis 17: 198.

7. Lawlor DA, Sattar N, Smith GD, Ebrahim S (2005) The associations of physical activity and adiposity with alanine aminotransferase and gamma-glutamyltransferase. Am J Epidemiol 161: 1081-1088.

8. Hong Z, Yanfang J, Shumei H, Jie S, Qing G, et al. (2012) Relationship between serum aminotransferase levels and metabolic disorders in northern China. Turk J Gastroenterol 23: 699-707.

9. Sharma AK, Metzger DL, Daymont C, Hadjiyannakis S, Rodd C (2015) LMS tables for waist circumference and waist-height ratio Z-scores in children aged 5-19 y in NHANES III: association with cardio-metabolic risks. Pediatr Res 78: 723-729.

10. Kuriyan R, Thomas T, Lokesh DP, Sheth NR, Mahendra A, et al. (2011) Waist circumference and waist for height percentiles in urban South Indian children aged 3-16 years. Indian Pediatr 48: 765-771.

11. Matthews DR, Hosker JP, Rudenski AS, Naylor BA, Treacher DF, et al. (1985) Homeostasis model assessment: insulin resistance and betacell function from fasting plasma glucose and insulin concentrations in man. Diabetologia 28: 412-419.

12. National center for health statistics (2017) Clinical Growth Charts. Centers for disease control and prevention (CDC), United States.

13. Schwimmer JB, Dunn W, Norman GJ, Pardee PE, Middleton MS, et al. (2010) SAFETY study: alanine aminotransferase cutoff values are set too high for reliable detection of pediatric chronic liver disease. Gastroenterology 138: 1357-1364.

14. National center for health statistics (2009) Z-score Data Files. Centers for disease control and prevention (CDC), United States.

15. El-Koofy NM, Anwar GM, El-Raziky MS, El-Hennawy AM, El-Mougy FM, et al. (2012) The association of metabolic syndrome, insulin resistance and non-alcoholic fatty liver disease in overweight/obese children. Saudi J Gastroenterol 18: 44-49.

16. Yan W, Liu F, Li X, Wu L, Zhang Y, et al. (2013) Blood pressure percentiles by age and height for non-overweight Chinese children and adolescents: analysis of the China Health and Nutrition Surveys 1991-2009. BMC Pediatr 13: 195

17. Falkner B, Daniels SR (2004) Summary of the Fourth Report on the Diagnosis, Evaluation, and Treatment of High Blood Pressure in Children and Adolescents. Hypertension 44: 387-388.

18. Yin J, Li M, Xu L, Wang $Y$, Cheng $H$, et al. (2013) Insulin resistance determined by Homeostasis Model Assessment (HOMA) and associations with metabolic syndrome among Chinese children and teenagers. Diabetol Metab Syndr 5: 71.

19. Genuth S, Alberti KG, Bennett P, Buse J, Defronzo R, et al. (2003) Follow-up report on the diagnosis of diabetes mellitus. Diabetes Care 26: 3160-3167.

20. Gröber-Grätz D, Widhalm K, de Zwaan M, Reinehr T, Blüher S, et al. (2013) Body mass index or waist circumference: which is the better predictor for hypertension and dyslipidemia in overweight/obese children and adolescents? Association of cardiovascular risk related to body mass index or waist circumference. Horm Res Paediatr 80: 170-178.

21. Ridker PM, Cannon CP, Morrow D, Rifai N, Rose LM, et al. (2005) $\mathrm{C}$-reactive protein levels and outcomes after statin therapy. $\mathrm{N}$ Engl J Med 352: 20-28.

22. Ridker PM, Danielson E, Fonseca FA, Genest J, Gotto AM Jr, et al. (2008) Rosuvastatin to prevent vascular events in men and women with elevated C-reactive protein. N Engl J Med 359: 2195-2207.

23. Ford ES, Li C, Cook S, Choi HK (2007) Serum concentrations of uric acid and the metabolic syndrome among US children and adolescents. Circulation 115: 2526-2532.

24. Church TS, Kuk JL, Ross R, Priest EL, Biltoft E, et al. (2006) Association of cardiorespiratory fitness, body mass index, and waist circumference to nonalcoholic fatty liver disease. Gastroenterology 130: 2023-2030.

25. Hernández MJG, Klünder M, Nieto NG, Alvarenga JCL, Gil JV, et al. (2018) Pediatric Visceral Adiposity Index Adaptation Correlates with Homa-IR, Matsuda, and Transaminases. Endocr Pract 24: 294-301.

26. Ha Y, Seo N, Shim JH, Kim SY, Park JA, et al. (2015) Intimate association of visceral obesity with non-alcoholic fatty liver disease in healthy Asians: A case-control study. J Gastroenterol Hepatol 30: 1666-1672.

27. Hong X, Wongtongkam N, Ward PR, Xiao S, Wang S, et al. (2016) An association of serum ALT with elevated blood pressure in senior adults: a case-control study. Clin Exp Hypertens 38: 691-695.

28. Bonnet F, Gastaldelli A, Pihan-Le Bars F, Natali A, Roussel R, et al. (2017) Gamma-glutamyltransferase, fatty liver index and hepatic insulin resistance are associated with incident hypertension in two longitudinal studies. J Hypertens 35: 493-500.

29. Fu S, Lin Y, Luo L, Ye P (2017) The relationship of serum alanine aminotransferase normal-range levels to arterial stiffness and metabolic syndrome in non-drinkers and drinkers: a Chinese community-based analysis. BMC Gastroenterol 17: 49.

30. Ma LN, DU R, Cheng D, Lin L, Wu XY, et al. (2019) Serum Alanine Aminotransferase Is Associated with Metabolic Syndrome and 10year Risk of Cardiovascular Disease. Biomed Environ Sci 32: 121-125.

31. Marchesini G, Bugianesi E, Forlani G, Cerrelli F, Lenzi M, et al. (2003) Nonalcoholic fatty liver, steatohepatitis, and the metabolic syndrome. Hepatology 37: 917-923. 